\title{
Paisaje urbano en las ciudades medias
}

Victor Fernández Salinas. Dpto. de Geografía Humana. Universidad de Sevilla.

\section{La mejor expresión de} espacios de vida en común se encuentra en las ciudades medias
Los mejores escenarios urbanos andaluces

Las ciudades medias del interior de Andalucía son el mejor ejemplo del carácter del paisaje urbano andaluz tradicional. Si se exceptúan los grandes monumentos de las capitales y grandes ciudades, el entramado urbano andaluz por antonomasia, el grano, el meollo de la inteligencia colectiva en la construcción de los espacios de vida en común, allí donde mejor se aprecia y donde está su mejor expresión, está en estas ciudades medias. Hasta hace pocos años han vivido un largo proceso de letargo y pérdida de pulso en todos los órdenes sociales y económicos que, no obstante, contrastaba con el espléndido producto que ofrecían en cuanto a combinación de inmuebles monumentales, sabia arquitectura popular y espacios públicos en perfecta armonía con los dos elementos anteriores. En los últimos decenios, se asiste a una revitalización de muchas de estas localidades, que reasumen de nuevo un papel destacado en la articulación del territorio

Las claves de este escenario urbano responden a una lógica de contrastes. Lo vertical versus lo horizontal, lo lujoso versus lo modesto, lo calculado versus lo espontáneo.
Aunque tal vez el par de conceptos enfrentados más importante sea el de lo sencillo versus lo complejo. En la aparente simpleza de líneas, colores y tramas que se yuxtaponen en armonía y se integran en formas netas en los fértiles terrenos de las campiñas y en las serranías interiores, subyace un calculado, antiguo y rico sistema de relaciones y valores intangibles que se hacen visibles a partir de los elementos físicos que conforman estas localidades: desde la conformación de sus plazas a los materiales y técnicas de techado. El desconocimiento de esta compleja personalidad urbana y su relación con el territorio lleva a que muchas localidades de interior pierdan o menoscaben precisamente aquello que está en lo más hondo de su personalidad. Los ejemplos de esto tienen que ver con procesos bien distintos como la alteración y/o desaparición de la arquitectura vernácula; la ignorancia de la forma en que, con frecuencia, estas localidades han integrado sus ríos y otros elementos naturales en su entramado urbano; la descomposición y caos de sus bordes urbanos; y así un largo etcétera que llega a las cuestiones de fondo y por consiguiente más importantes: la subestima, quiebra y pérdida de los saberes inmateriales propios. 


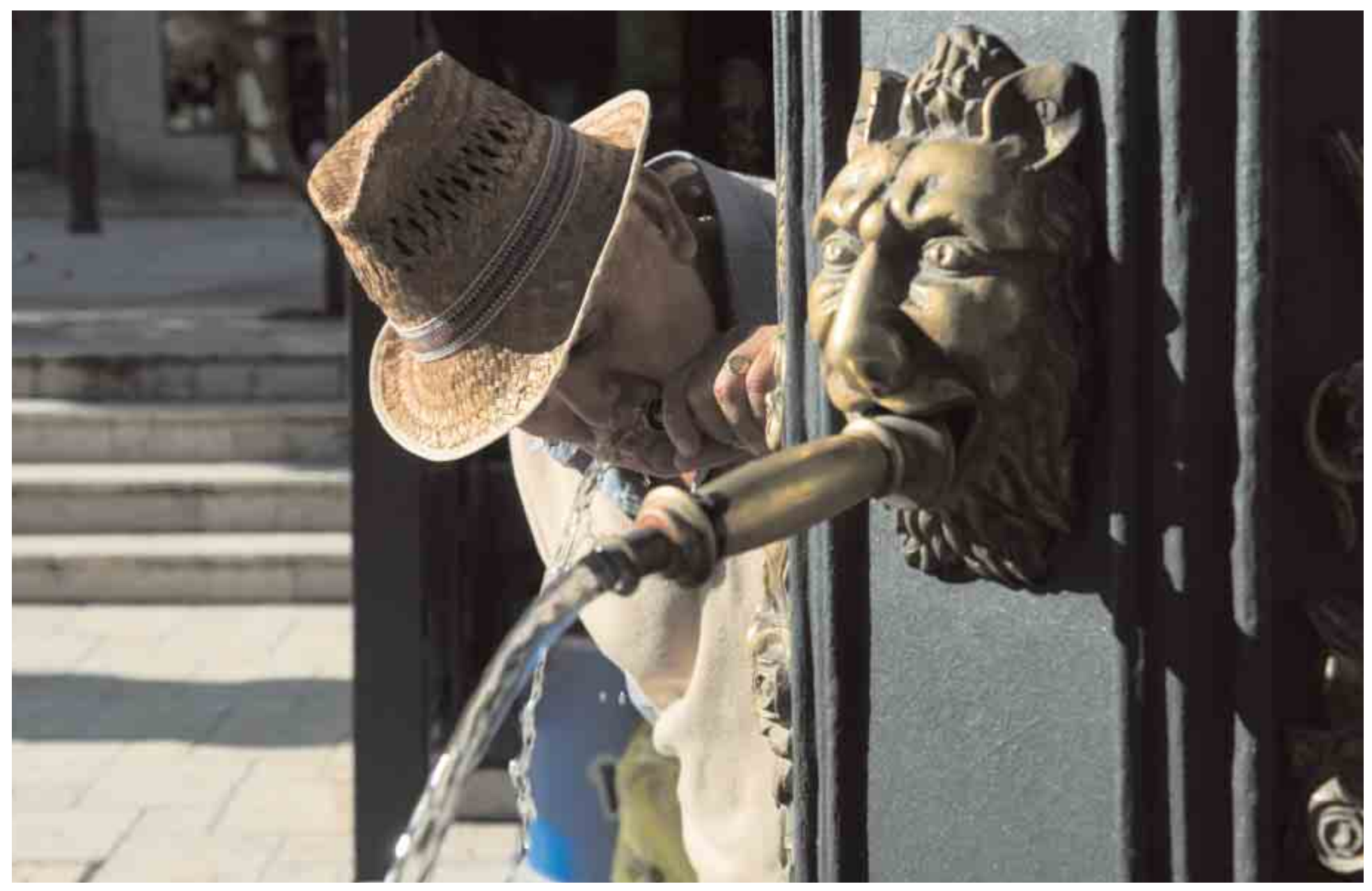


Los viejos lugares comunes asentados en el siglo XIX a partir de la mirada costumbrista, que dibujaban una arcadia idealizada, han forjado una visión inmovilista y lánguida que es difícil desterrar y que salpica las expresiones artísticas desde la literatura al cine (desde las obras de los hermanos Quintero al cine de Summers).

Esta mezcla de escenario costumbrista $y$, al mismo tiempo, la mejora en las rentas familiares y los cambios rápidos en los valores y aspiraciones de muchos habitantes de estas localidades, ha hecho emerger una cultura urbana en los últimos años que, sin abandonar los tintes regionalistas y un tanto tópicos, se ha recargado con un lenguaje más pretencioso y neobarroco, en el que su mejor expresión es la generalización de la arquitectura abalaustrada que tanto aparece en las nuevas urbanizaciones, legales o no, que han crecido en los últimos decenios en torno a muchas de estas ciudades.

\section{Los retos para una cultura del paisaje nueva en las ciudades medias}

Hablar de retos es hablar de exigencias urgentes y perentorias ante la rapidez de muchos procesos urbanos de difícil control. Podría hablarse de dos exigencias principales:

La más importante es la recuperación imperiosa de la autoestima respecto a los valores locales, tan mermada tras decenios, por no decir siglos, de un declive social, económico y cultural que ha llevado a que las decisiones importantes sean tomadas cada vez más lejos (capitales provinciales, Sevilla, Madrid, Bruselas....). Esta recuperación de la autoestima debe reflejarse especialmente en los programas formativos, sobre todo en los básicos, pero también en los universitarios y en la formación permanente. Los programas triunfalistas, estéticos, superficiales y cutáneos, de clara vocación turística no sirven más que para intentar potenciar la atracción de un sector económico, el turísti- co, de estas localidades. Estos programas se limitan a destacar la importancia de los testigos barrocos como un argumento nostálgico que retrotrae siempre la vitalidad de estas localidades a la época moderna y, probablemente, a un tiempo que nunca fue, o en todo caso que fue espléndido para la aristocracia terrateniente y para las órdenes religiosas. El sector turístico es importante, pero las ciudades medias interiores andaluzas lo que precisan son documentos más amplios en los que diseñar su modelo de desarrollo para, después, reconocer la aportación que cabe esperar del patrimonio. Abogar por el paisaje sin tener en cuenta los procesos socioeconómicos de los que es reflejo es como pretender evaluar el proceso de maduración de un individuo a partir de la ropa que se pone, y no de otros procesos psíquicos y físicos que realmente condicionan su aspecto. El paisaje de estas ciudades, y su protección, no es un fin en sí mismo, sino un vehículo a partir del cual valorar la madurez e inteligencia colectivas.

Desde un punto de vista patrimonial, es necesario un cambio en la perspectiva del planeamiento espacial. Es fundamental el desarrollo de planes de ordenación territorial que articulen las zonas interiores de Andalucía y que señalen el papel central de estas localidades, no sólo en su perspectiva de competencia, sino de complementariedad. No parece ser ésta la prioridad de la administración que, ante los procesos más dinámicos de las zonas urbanas y litorales, posponen las interiores como si en ellas los nuevos procesos espaciales tuvieran menos importancia o menos urgencia. El valor paisajístico de la ciudad interior se basa en una parte sustancial en su integración territorial, por ello también es imprescindible que los documentos urbanísticos municipales incorporen esta premisa, casi siempre sometida a otras necesidades o presiones, como la localización de polígonos industriales o nuevos sectores residenciales, que ha deteriorado gravemente el contexto de poblaciones como Las Cabezas de San Juan, Arahal o la propia Antequera en alguna 


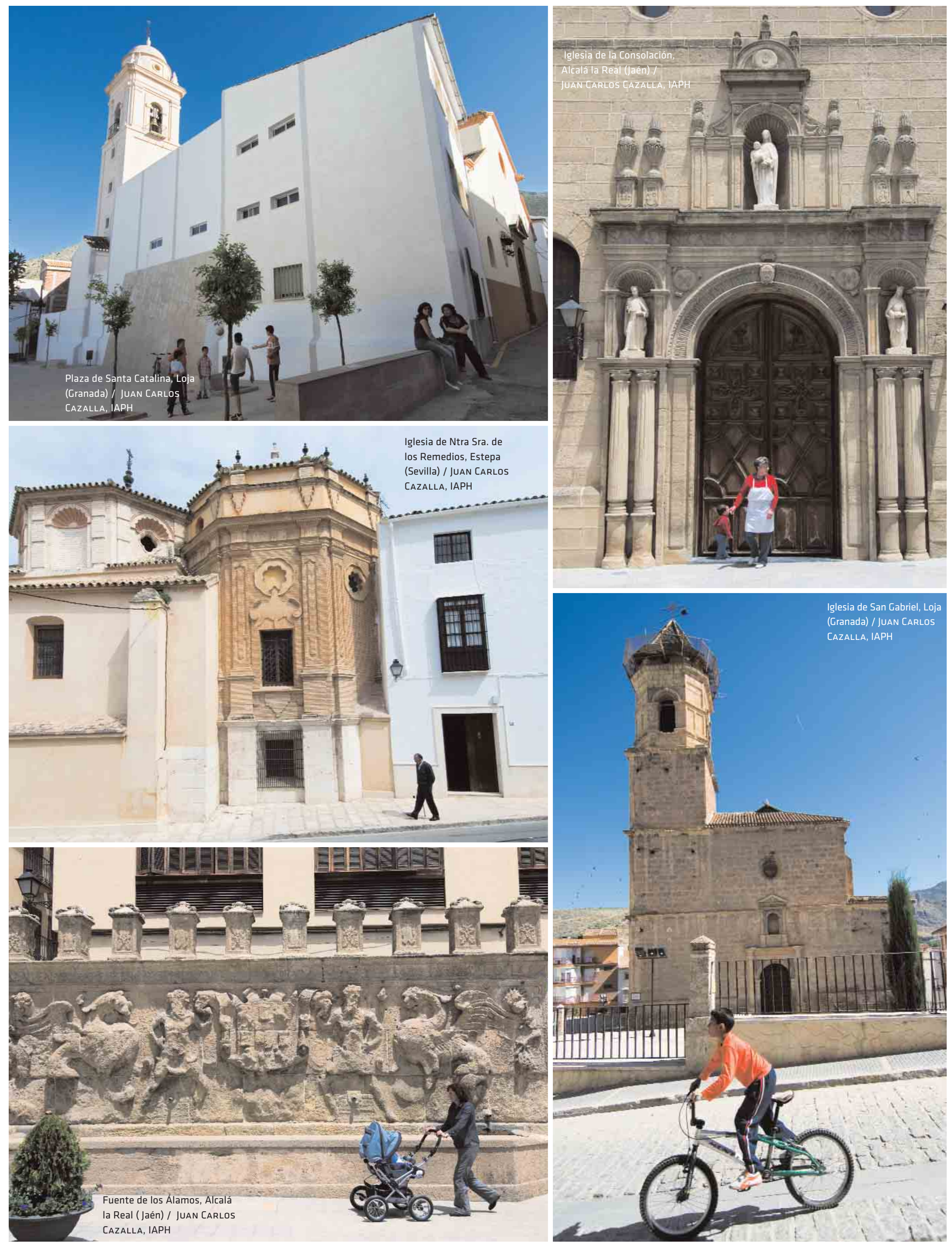




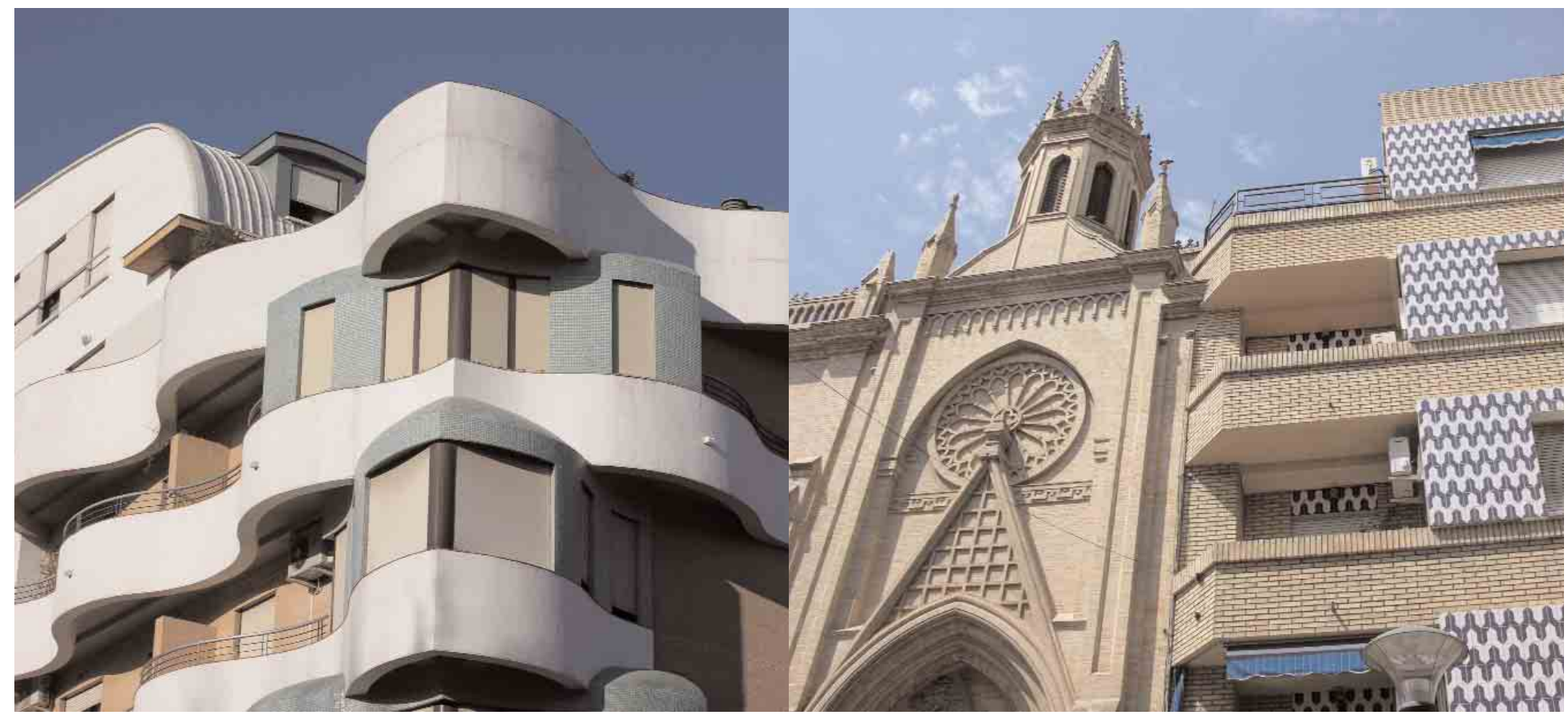

Cambios del paisaje en las ciudades medias. De izquierda a derecha: Úbeda (Jaén), Andújar (Jaén), Morón de la Frontera (Sevilla) y Úbeda (Jaén) / Víctor Fernández SALINAS

La sobrevaloración de

los valores urbanos

frente a los rurales

produce un rápido e

irreparable cambio de

paisaje de las colinas próximas. Los planes generales de ordenación urbanística deben incorporar la idea de que el carácter histórico de estas ciudades (Úbeda, Ronda, Priego de Córdoba, Écija...) no termina en los límites, cuando lo tienen, de su conjunto histórico, y que este carácter debe mantenerse, incluso en las claves de la modernidad, en todos los espacios de estas localidades. Guadix o Medina Sidonia son ciudades históricas, y por lo tanto responsables de un paisaje de honda raigambre histórica en el dédalo de sus calles más antiguas, pero también en los barrios y sectores que están siendo proyectados y construidos hoy. También hay que introducir nuevos criterios de salvaguarda de espacios públicos y arquitecturas populares en los planes especiales de protección de conjuntos históricos. Aunque dentro de la atonía general de elaboración de estos planes se pueda argumentar que varias de las más monumentales ciudades de interior ya los tienen (Baeza, Antequera, Écija...), se puede afirmar que la protección de la arquitectura más modesta y popular es escasa, está minusvalorada y mengua día a día; puede 


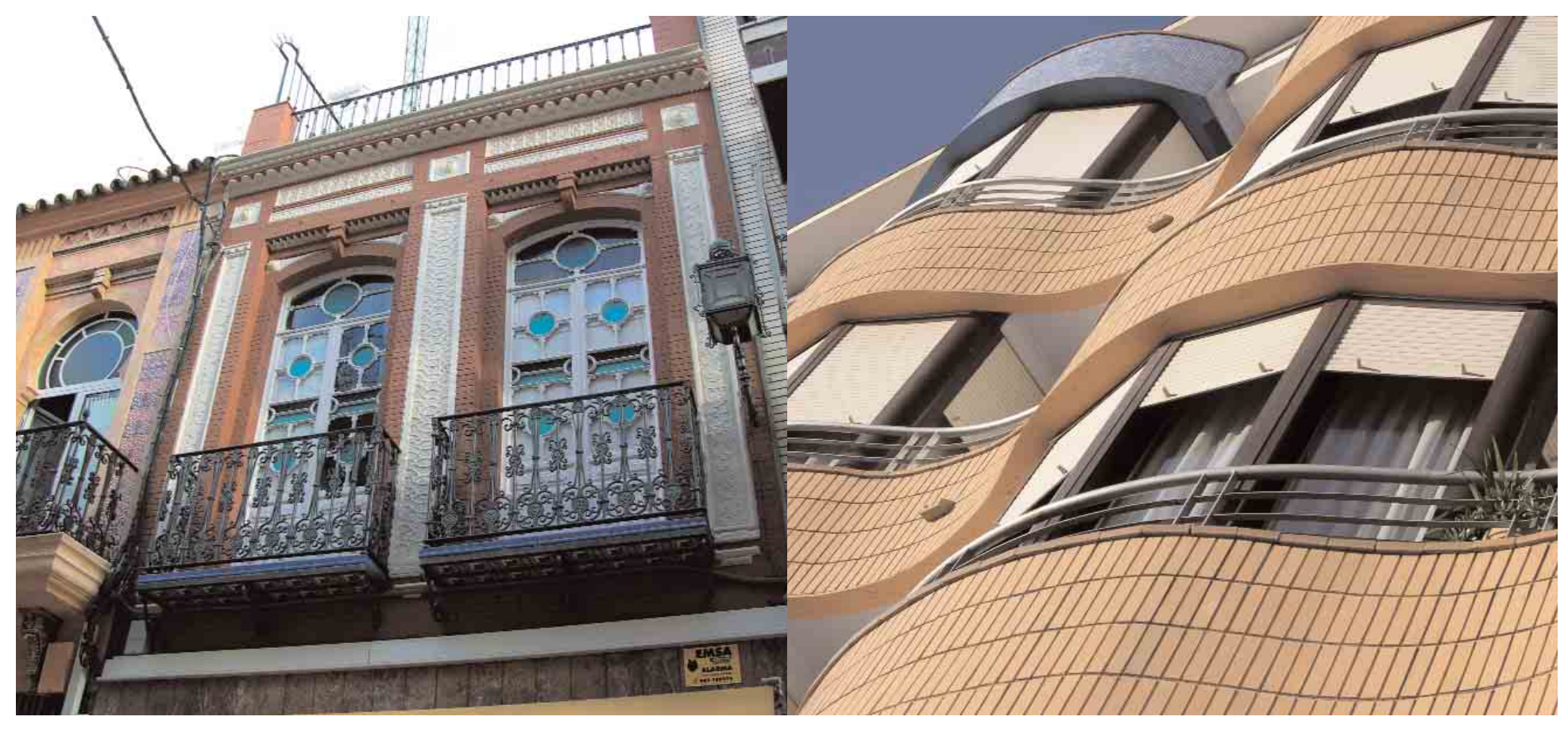

afirmarse que es la parte del patrimonio andaluz que, con la arquitectura industrial, está desapareciendo de forma más rápida. Sin promoción de los valores de estas tipologías, con una sobrevaloración de los valores urbanos frente a los rurales y con el citado incremento de las rentas familiares, se está produciendo un rápido e irreparable cambio del paisaje de muchas de estas localidades.

No hay recetas fáciles ni rápidas para la preservación de los paisajes de las localidades de interior -ni del territorio en general-. Las normas y planes sirven de poco si no existe una base social que comprenda y asuma la importancia del paisaje como recurso social. La administración de Cultura en Andalucía es la que debe liderar los procesos de estudio y conservación del paisaje, asumidos principalmente hasta el momento por la Consejería de Obras Públicas y Transportes, como demuestra la aparición del Centro de Estudios Paisaje y Territorio (véase p. 24). Los últimos años permiten un cierto optimismo con la creación de la Comisión del Paisaje Cultural en el Instituto Andaluz del Patrimonio Histórico (remitimos a breves de PH 62), consolidando una línea de investigaciones que desde hace tiempo se centra en el análisis aplicado de las políticas del paisaje y que motivó la creación del Laboratorio del Paisaje. Esta labor debe complementarse con otras acciones, tanto en los órganos centrales de la Consejería de Cultura, como en sus delegaciones provinciales. No obstante, los tiempos que corren no permiten ser del todo optimistas. Si en la propia Sevilla, la construcción de un rascacielos de 180 metros de altura alterando el paisaje histórico de la ciudad no ha suscitado una actitud estricta y responsable de la administración cultural, no parece que aspectos que afecten a localidades del interior, sólo evocadas a menudo a partir del esplendor de su barroco, vayan a tener una atención mejor. La forma y los valores caminan juntos en el paisaje urbano. Aún hay lecciones no estudiadas y que son claras como un libro abierto en los paisajes urbanos de la equilibrada y valiosa red de ciudades medias andaluzas. 


\section{Úbeda-Baeza: enclave dual del Renacimiento español}

La dimensión patrimonial de las ciudades medias andaluzas es un hecho incuestionable, que pone de relieve la fortaleza del sistema urbano andaluz a lo largo de la historia. Ciudades que han desempeñado las principales funciones de articulación del territorio andaluz, entre ellas Úbeda y Baeza, fueron declaradas Patrimonio de la Humanidad por la UNESCO en julio de 2003. Una declaración que giraba en torno a una palabra clave, la dualidad: un enclave urbano dual, una realidad patrimonial compuesta por dos ciudades que se explican como suma, lo que constituye su verdadera excepcionalidad y el primer caso de una inscripción de este tipo.

Justificar sus valores universales suponía construir un argumento patrimonial unitario e integrador a partir de tres elementos clave de su aportación al Patrimonio Mundial: dualidad urbana excepcional, sin duda; pero también originalidad artística y, a través de ésta, su proyección cultural en Iberoamérica.

Una dualidad urbana complementaria pues en cierto sentido operan como una sola ciudad que domina su territorio inmediato, relación que se hará especialmente intensa durante el Renacimiento coincidiendo con su plena madurez urbana y patrimonial. Una estructura territorial excepcional que no conoce otra situación análoga de dos ciudades de rango equivalente, y tan próximas, que hayan mantenido permanentemente tal situación de paridad.

Esta bicefalia obedece a una dualidad de poderes: en Úbeda, el poder civil, representado por Francisco de los Cobos, influyente Secretario del Emperador Carlos V; y en Baeza, donde el poder del Estado y de la Iglesia serán deudores de su fidelidad desde los primeros tiempos de conquista, circunstancias que explican su complementariedad funcional y su especialización: Úbeda, sede residencial de las principales familias aristocráticas; y Baeza, excepcional centro administrativo, religioso y académico; todo ello en un contexto histórico propio de un territorio de frontera proclive a las libertades y abierto a influencias que favorecieron su espléndido florecimiento cultural y urbano durante el siglo XVI. Dualidad que también se refleja en los modelos de transformación urbana que experimentan cada ciudad, complementarios al mostrar un repertorio de ideas y soluciones del urbanismo renacentis ta, con la originalidad de adaptarlas a una realidad muy distinta de la italiana.

Finalmente, su originalidad artística se debe a una fructífera sintesis entre la tradición medieval de la cantería jiennense y la herencia de sus raíces islámicas, que se enriquecen con la innovación constructiva y la reinterpretación del lenguaje clásico aportados por Andrés de Vandelvira. Una expresión artística que influirá notablemente en numerosas construcciones militares o religiosas como las catedrales de México, Puebla, Mérida, Guadalajara, Oaxaca, Lima o Cuzco, algunas también declaradas Patrimonio Mundial.

Pero la propuesta de declaración no sólo interpretaba sus valores patrimoniales, también pretendía poner en valor sus respectivos centros históricos que en este tipo de ciudades medias pueden ser aún más sensibles a la competencia que sobre ellos ejercen las nuevas áreas de crecimiento. Lograr su reactivación funcional o potenciar su integración con el paisaje han sido objetivos de los Programas de las Áreas de Rehabilitación Concertada que, fruto del impulso de su declaración, actualmente se llevan a cabo en cada ciudad. Un compromiso en la protección y gestión de sus recursos patrimoniales que Úbeda y Baeza deben asumir a la medida de este reconocimiento.

Rufina Fernández Ruiz

Arquitect
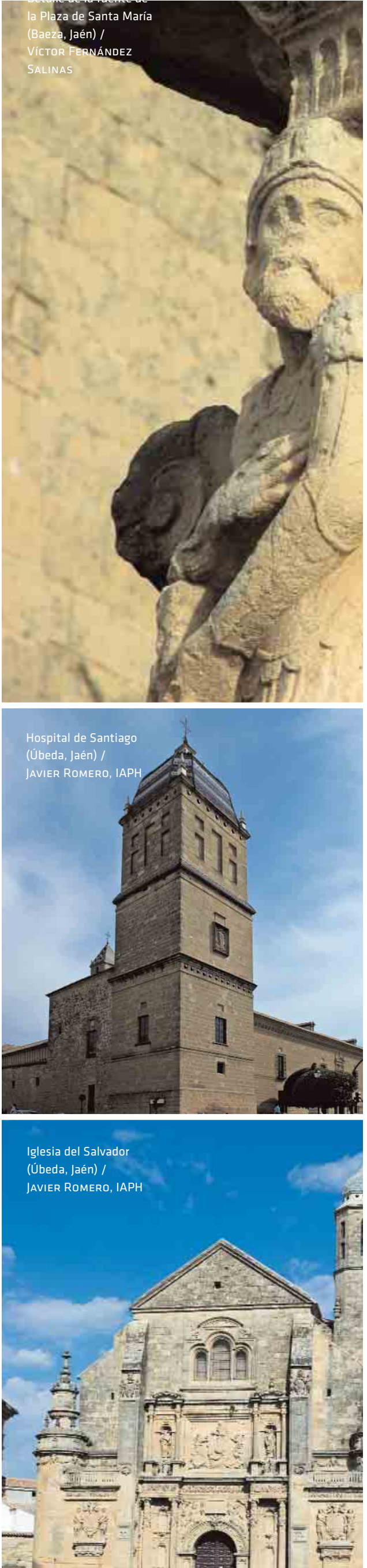


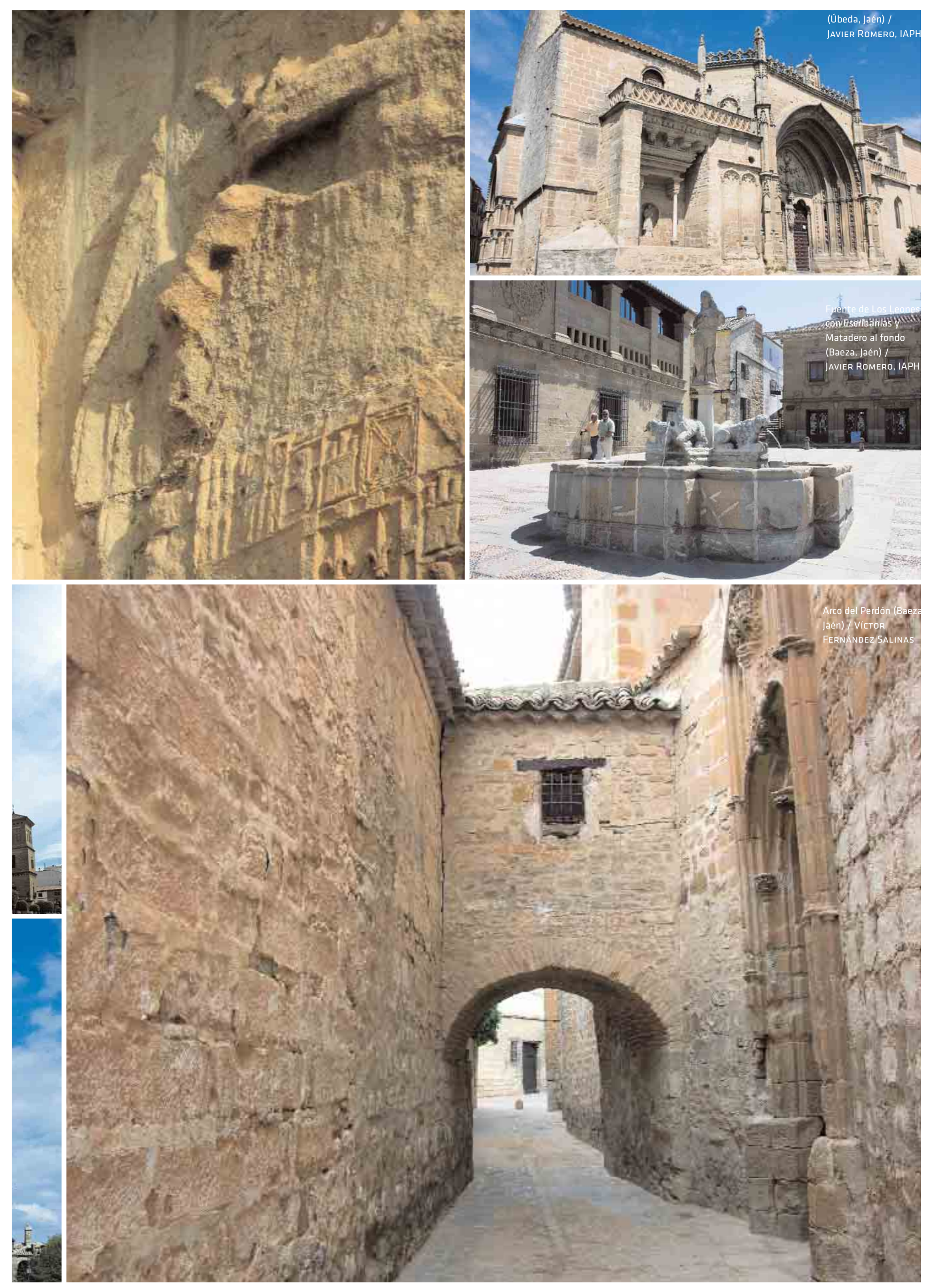

